\title{
Los invisibles en el laberinto del minotauro o la lucha por el derecho a la justicia en Colombia*
}

\author{
Luis Alfonso Fajardo SánChez
}

Fecha de recibido: 16 de febrero de 2006

Fecha de aprobación: 14 de marzo de 2006

\section{RESUMEN}

El artículo establece un análisis de nuestra realidad sociopolítica y las necesidades de acceso a la justicia de los sectores menos favorecidos de nuestro país, sectores que luchan por lograr una justicia pronta y material; en su reflexión el autor recoge el Programa Nacional de Casas de Justicia, política pública creada en el por el decreto 1477 del 2000 con el fin de facilitar a las comunidades de menores recursos el acceso a la justicia, y lo relaciona con necesidades concretas de los grupos étnicos, los habitantes de la calle, los adultos mayores y los desplazados.

\section{PALABRAS CLAVE}

Derechos humanos, acceso a la justicia, desplazados, pobres, habitantes de la calle.

\section{ABSTRACT}

The article makes an analysis about our sociopolitical reality and the needs of access to justice of the less favored social classes, sector that struggles to get a promptly and real justice. In this reflection the author

Docente de tiempo completo en la Facultad de Derecho de la Universidad Santo Tomás. El Presente articulo se basa en la Investigación "Acceso a la justicia de sectores en condiciones especiales de vulnerabilidad en el Programa Nacional de Casas de Justicia" que actualmente desarrolla la línea de Investigación de "Derecho y Sociedad" de la Facultad de Derecho de la Universidad Santo Tomás, reconocido por COLCIENCIAS en 2004, actualmente en categoría B. Participan en la Investigación: Coordinador: Dr. Luis Alfonso Fajardo Sánchez; las jóvenes investigadoras: Luisa Fernanda García Lozano y Diana Carolina Abondano Lozano, y las asistentes de investigación: Lina Victoria Barón Cabrera y Camila Alejandra Hoyos Pulido. 
picks up the National program of Justice Houses, public policy created by decree 1477 of 2000 , in order to facilitate to the less income communities the access to Justice. This is related with the specific necessities of the ethnic population, the homeless people, the elders and the displaced people.

\title{
KEY WORDS
}

Human Rights, access to justice, displaced people, poor people, homeless people.

\begin{abstract}
Minotauro: monstruo mitológico, mitad ser humano y mitad toro, nacido de los amores de Pasifae (esposa de Minos, rey de Creta) y un toro. Para esconder semejante vergüenza, Minos ordenó a Dédalo construir un Laberinto, en donde fue encerrado el monstruo. Luego, el propio Dédalo y su sobrino ícaro fueron encerrados en el laberinto, pero consiguieron escapar gracias al ingenio de Dédalo. Minos exigió a los atenienses, como tributo, varios muchachos y muchachas cada siete años, para servir de alimento al monstruo.
\end{abstract}

\section{Presentación}

Una de las más hermosas novelas del escritor peruano Manuel Scorza, "La historia de Garabombo el invisible", nos narra el drama de un indígena, de los páramos de Ayacucho en Perú, que se siente invisible. Garabombo era invisible porque el poder político y el poder económico no lo veían. Las instituciones del Estado, el gobierno, nunca lo vieron. Garabombo se paseaba tranquilamente entre las tropas que venían a someterlos y nunca lo vieron.

En Colombia la historia de los invisibles se cuenta por millones... de desplazados, de indígenas, de afrocolombianos, de niños, niñas y mujeres maltratados. Los invisibles van de puerta en puerta solicitando, reclamando, mendigando sus derechos y las instituciones nunca o pocas veces los ven. Los invisibles avanzan por todos los caminos del laberinto, donde abundan las puertas de entrada pero escasas puertas de salida.

Los invisibles en el laberinto de un sistema económico, político y jurídico que muchas veces sacrifica a quienes recorren sus senderos tortuosos y oscuros. El sistema invisibiliza y, como el minotauro, exige como tributo la miseria, el olvido y no pocas veces, la vida.
Las esperanzas de los invisibles, en el caso colombiano, se encuentran en muchas puertas, una de ellas es el Programa Nacional de Casas de Justicia, que intenta llevar la justicia al lugar del laberinto donde se encuentran los invisibles; allí, en los sitios de mayor conflictividad y pobreza, allí donde el laberinto se ha vuelto más desesperanzador, allí las Casas de Justicia se han propuesto abrir una puerta de salida del laberinto.

El presente trabajo es fruto de los avances de la investigación "Acceso a la justicia de sectores en condiciones especiales de vulnerabilidad en el Programa Nacional de Casas de Justicia", que se viene desarrollando en el Centro de Investigaciones "Francisco de Vitoria" de la Facultad de Derecho de la Universidad Santo Tomás en Bogotá.

\section{Introducción}

El aumento de los niveles de pobreza, la prolongación del conflicto armado interno, el desplazamiento forzado, han incrementado en la población las necesidades sociales y las dificultades de acceso a la justicia. Esta situación se acentúa en sectores como: habitantes de calle, trabajadores/ as sexuales, pueblos indígenas, comunidades afrocolombianas, adultos mayores y comunidades desplazadas, y se manifiesta en la falta de imple- 
mentación de las políticas públicas para estos grupos sociales, lo cual ha dificultado la solución concreta y efectiva de los problemas.

La Facultad de Derecho de la Universidad Santo Tomás, en la búsqueda de impulsar experiencias que sirvan como aporte en la teoría de la justicia en donde el derecho se convierta en una herramienta de la justicia social, ha incluido dentro de la Línea de investigación Derecho y sociedad el desarrollo de estos temas.

La presente investigación pretende, a través del análisis del contenido material del derecho fundamental de acceso a la justicia, crear un Protocolo de Atención para ser implementado, como el desarrollo de una acción afirmativa por parte del Estado Colombiano en el marco del Programa Nacional de Casas de Justicia, con el objeto de fortalecer las políticas públicas para garantizar este derecho, teniendo en cuenta diferencias étnicas, culturales, de género y generacionales, que constituyen un elemento esencial para el tratamiento de las necesidades y demandas de justicia de estos sectores de manera efectiva.

La Constitución Política, en el Art. 229, establece: "Se garantiza el derecho de toda persona para acceder a la administración de justicia". Este precepto es el fundamento del esfuerzo del Gobierno para garantizarlo por medio, entre otros espacios, del Programa Nacional de Casas de Justicia y Paz creado para el servicio de aquellos sectores que por sus condiciones de pobreza o marginalidad tienen un acceso restringido al aparato de justicia estatal.

La investigación gira entorno a la pregunta: ¿Están dando respuestas las Casas de Justicia del país a los reclamos de acceso a la justicia de los sectores en condiciones de vulnerabilidad, como lo son Ios Pueblos indígenas, comunidades afrocolombianas, personas desplazadas por la violencia, adultos/as mayores, trabajadores/as sexuales $y$ habitantes de la calle, a través de una oferta institucional orientada a estos grupos cuya problemática se ha agravado como consecuencia del conflicto social y armado que vive el pais?

\section{Construcción de los caminos del laberinto}

A partir de la década de los noventa, con el recrudecimiento de la guerra en Colombia, los contextos sociales, económicos y políticos del país se revisten de situaciones de desigualdad y violencia que impiden la creación de condiciones que satisfagan la necesidad de justicia de amplios sectores de la sociedad, generando un clima de inseguridad y anomia jurídica. Entre los principales factores identificados que obstaculizan el acceso a la justicia y al aparato judicial se encuentran: i) geográfico, que se refiere a las limitaciones especiales que aquejan a muchas comunidades para acceder al servicio de justicia; ii) económico, debido a que los costos de los procesos (civiles, penales, laborales, etc.) son elevados, dejando a muchos sectores de la población vulnerable, sin capacidad para acudir ante las instancias judiciales, y por último, iii) el factor cultural que tiene relación con el desconocimiento de la ley y de sus procedimientos.

En razón a estos contextos, es frecuente la reclamación al Estado por la adopción de medidas tendentes a posibilitar la materialización de los derechos en general, impulsando así diversas políticas, acciones y programas para acercar la justicia a aquellas comunidades que históricamente no podían acceder a ella. Sin embargo, existen ciertos sectores que por sus características especiales (étnicas, de género, generacionales y culturales) requieren que dentro de los mecanismos antes descritos se implementen programas que eliminen o reduzcan las desigualdades, para así garantizar efectivamente la realización de sus derechos constitucionales y legales. 
Uno de los mecanismos creados por el Estado colombiano para concretar estas políticas es el "Programa Nacional Casas de Justicia y Paz", que de acuerdo con el decreto 1477 de 2000 tiene por objeto "facilitar a la comunidad el acceso a la justicia, prioritariamente en las zonas marginales..."; la investigación intenta determinar cuál es la oferta de justicia para seis (6) sectores en altas condiciones de vulnerabilidad: pueblos indígenas, comunidades afrocolombianas, habitantes de la calle, adultos mayores, personas y comunidades desplazadas por la violencia y trabajadoras/es sexuales.

\section{Desentrañando el laberinto: la búsqueda de metodologías no estáticas}

Para dar respuesta y un parámetro guía a la investigación se ha planteado como objetivo general: evaluar las formas de acceso a la justicia ofrecidas desde las Casas de Justicia a grupos de población en condiciones altas de vulnerabilidad. Así mismo, se determinaron los siguientes objetivos específicos: a) estudiar las dificultades u obstáculos y los niveles de eficiencia de las formas de acceso a la justicia a estos sectores; b) elaborar un Protocolo de Atención para garantizar el acceso a la justicia de estos sectores especialmente vulnerables; y c) preparar un informe sobre la situación de las Casas de Justicia respecto a estos sectores vulnerables.

Se escogió una muestra de 11 Casas de Justicia ubicadas en diferentes ciudades del país, en las cuales se ha venido realizando el trabajo de campo, así: Cartagena - Country, Barranquilla - La Paz, Puerto Asís, en Bogotá y Cundinamarca, las Casas de Ciudad Bolívar y Soacha, Cali - Aguablanca, Valledupar, Pereira - Cuba, Popayán, Quibdó y Villavicencio.

Se diseñó una metodología que posibilitara hallar los resultados requeridos y llegar a conclusio- nes certeras. Muchas son las metodologías propuestas, las discusiones que se han presentado y las obras que se han escrito sobre este tema, pero parece que la afirmación más acertada continúa siendo la del pensador alemán Paul Feyerabend, quien en sus obras demuestra que no hay metodología infalible y no pocas veces la definición puntual de una metodología se convierte en una barrera en el proceso del conocimiento. Feyerabend nos comenta en su obra Contra el método:

Queda claro, entonces, que la idea de un método fijo, o de una teoría fija de la racionalidad, descansa en una imagen demasiado simple del hombre y sus circunstancias sociales. Para aquellos que contemplan el rico material proporcionado por la historia y que no intentan empobrecerlo para satisfacer sus instintos más bajos o sus deseos de seguridad intelectual en forma de claridad, precisión, «objetividad» o «verdad», estará claro que sólo hay un principio que puede defenderse en todas las circunstancias y en todas las etapas del desarrollo humano. Este principio es "todo se vale".

Para el desarrollo de la investigación nos identificamos con los principios de la investigación social, especialmente con uno de sus fundamentos principales: facilitar el conocimiento de una determinada realidad que contribuya a una acción política y social transformadora de ésta, descubriendo las voces de los marginados y excluidos no solo del sistema jurídico, sino de la misma sociedad. En este sentido, se han identificado las entidades que hacen parte del Programa de Casas de Justicia en cada uno de los sitios que son objeto del proyecto, acercándonos a los funcionarios para constatar si existe alguna oferta para los sectores vulnerables, si es posible aplicar en las Casas de Justicia programas diseñados por instituciones como la Defensoría del Pueblo, las personerías municipales, las comisarías de familia, entre otras, para dichos grupos; es igualmente importante analizar cuál es la propuesta 
desde la experiencia de cada uno de los funcionarios de las Casas de Justicia y determinar la proximidad de éstos con las comunidades presentes en su área de influencia.

Estos son los elementos más relevantes del proyecto de investigación. En últimas, el objetivo que persigue es delinear el sueño de una justicia incluyente, en donde se le dé una oportunidad a los sectores vulnerables para que visibilicen sus necesidades de justicia y que nosotros como sujetos posibles, trasformadores de los conceptos de justicia y derecho, aportemos una herramienta que permita el acercamiento a este sueño.

\section{Se abre una puerta al final del laberinto: momento histórico de nacimiento del Programa Nacional de Casas de Justicia y Paz}

Los registros históricos de un país como Colombia están marcados por el conflicto, las fuertes desigualdades sociales ("niveles de pobreza rural que varían entre el 40 y el $80 \%$ los últimos 20 años $\left.{ }^{11}\right)$, los factores reales de poder en manos de pocos y regidos por la corrupción, ineficacia en la administración de justicia, violaciones constantes a los Derechos Humanos ${ }^{2}$ y una violencia política que degeneró en conflicto armado, más o menos desde 1946, permite evidenciar cómo, a principios de la década de 1990 , se presenta una coyuntura propicia para la creación de un programa como el de las Casas de Justicia, como garantía para la reivindicación del derecho de acceso a la justicia consagrado en la Carta Política de 1991. A continuación se presentarán algunos de los aspectos generales más relevantes que permiten situar el contexto en el que nace dicho Programa.

A pesar de los Acuerdos de Paz realizados entre el gobierno y grupos insurgentes desde la segunda mitad de la década de 1980, como el M-19 y el EPL, el conflicto continuó. En el período de 1989 a 1995, los actores armados: ELN, FARC y los diferentes grupos paramilitares, se disputaban el control territorial de grandes zonas provocando, entre otros fenómenos, un cambio de los contextos sociales al profundizar el desplazamiento forzado de miles de familias en todo el país ${ }^{3}$ (para 1995 existían alrededor de 600.000 personas desplazadas aproximadamente según las Observaciones finales del Comité de Derechos Económicos, Sociales y Culturales: Colombia. 06/12/95. E/ C.12/1995/18 par. 173-202 (Concluding Observations/Comments).

Los niveles de inequidad social se han incrementado drásticamente, si se tiene en cuenta que la línea de pobreza aumenta en momentos en los que la economía logra altas tasas de crecimiento. "Parecería como si la mitad de la sociedad colombiana estuviera condenada a vivir en condiciones de pobreza, aún en la fase ascendente del ciclo económico" ${ }^{4}$. Esta situación se encuentra emparentada con los escandalosos índices ${ }^{5}$ de desempleo y el bajo poder adquisiti-

PNUD. Conflicto, callejón con salida. Informe Nacional de desarrollo Humano. Bogotá, 2003.

2 Amnistía Internacional insistió para el año 1993 en reiteradas ocasiones al Gobierno que realizara investigaciones eficaces e imparciales sobre los informes de casos de ejecución extrajudicial "desaparición forzada" y tortura e hizo llamamientos para que los responsables de estos actos fueron puestos a disposición de los tribunales de justicia.

3 "La lucha por controlar territorios desemboca muy pronto en el terror; pero el terror a su vez desencadena un espiral que bajo ciertas condiciones, puede no tener más límite que el exterminio de la población local". PNUD, Op. cit, 2003, p. 90.

4 GONZÁLEZ, Jorge Iván. “Desigualdad y pobreza”. En: Reelección: el embrujo autoritario continúa. Segundo año de gobierno de Álvaro Uribe Vélez. Plataforma Colombiana de Derechos Humanos. Bogotá, 2004.

5 Consuelo Ahumada señala los siguientes indicadores: 1. Aumento del desempleo y su disociación con el crecimiento económico; 2 . Aumento de la informalidad, siete de cada diez empleos urbanos se han generado en el sector informal; 3 . En los noventa, los salarios reales aumentaron pero no alcanzaron los niveles previos a la crisis de la deuda. 
vo de los salarios que no contribuyen a que el crecimiento sea sostenible y equitativo ${ }^{6}$. Tal como se demuestra en diversos estudios en donde se ha determinado que: "la localización de la población en una situación extrema de pobreza y de indigencia se encuentra en la periferia de la ciudad, donde buscan asentarse las familias desplazadas víctimas de la violencia que llegan a la ciudad e intentan sobrevivir con lo poco que pudieron sacar de sus lugares de origen"".

De igual forma, la relación entre el narcotráfico como fuente principal de la economía informal del país y los grupos al margen de la ley, ha conllevado a que la mayoría de los esfuerzos de los gobiernos de Colombia y Estados Unidos se centren, durante estos años, en la creación de una política antidrogas, en la modernización de los aparatos de investigación y de justicia penal y en la reducción de la corrupción del Estado ${ }^{8}$.

Entre 1992 y 1995 Colombia se vio fuertemente afectada por diferentes problemas de índole social, política y económica, que trajeron consigo las movilizaciones sociales, huelgas y reivindicaciones sociales. Este contexto trajo consigo nuevas víctimas de la intolerancia por parte de los actores armados. Uno de los grupos más afectados son los sindicalistas, líderes sociales y sectores en situación de alta vulnerabilidad, como trabajadores/as sexuales y habitantes de la calle ${ }^{9}$. No obstante, los líderes sociales y los grupos vulnerables no son las únicas víctimas de la violencia sociopolítica, sino que en gran parte también son afectados los campesinos, quienes se ven forzados a desplazarse dejando todo lo que habían construido con el fin de "...ir en busca de un nuevo lugar en donde, por lo menos, tengan derecho a vivir"10.

Los más afectados por estos desplazamientos son los niños, los ancianos y las mujeres. La violencia provenía de todos los grupos armados de acuerdo a las continuas denuncias de organizaciones nacionales e internacionales de derechos humanos. Pero también de "las fuerzas armadas y los grupos paramilitares, que seguían actuando con su apoyo o aquiescencia"11, los cuales, según los informes de estas organizaciones, dieron muerte a por lo menos mil personas. Pero esto ocurrió no solo en zonas rurales, ya que también se recibieron informes acerca de policías que respaldaron las atrocidades generadas por los denominados escuadrones de la muerte, quienes asesinaban a los llamados indeseables sociales, entre ellos niños sin hogar, homosexuales o presuntos delincuentes, quienes eran acribillados o raptados en camionetas sin matrículas para aparecer después muertos, rara vez eran identificados, más aún, también se dedicaron a amenazar y a matar dirigentes comunitarios, estudiantes y jóvenes desempleados de barrios marginados ${ }^{12}$.

En esta época se denuncian, por parte de las organizaciones de derechos humanos, personas desaparecidas presuntamente a manos de las fuerzas militares y de integrantes de la policía nacional; se iniciaron los procesos de judicialización, sin embargo esas investigaciones no prosperaron ${ }^{13}$.

\footnotetext{
Basado en Reflexiones: escenario social de la administración de justicia, escrito por Fabio Castro Herrera. En imprenta.

Cien Días vistos por CINEP. "Cercados por la pobreza". Se han denominado hogares con pobreza aquellos cuyo ingreso no es suficiente para cubrir los requerimientos mínimos de la canasta de consumo obrero, es decir, alimentos, salud, educación, servicios públicos, etc. Los hogares en indigencia, por su parte, son aquellos cuyos ingresos no alcanzan ni siquiera para cubrir el costo de la canasta mínima de alimentos.

8 Ibíd., p. 168.

9 CASTELLANOS, Camilo. Revista Cien Días vistos por CINEP. "Sueños de paz". Bogotá, 1993.

10 GUERRERO, Amparo Elisa. Revista Cien Días vistos por CINEP. "Nunca imaginé ver todo lo que he visto". Bogotá, 1993.

1 Informe de Amnistía Internacional 1993, Colombia.

12 Ibíd.

13 Ibíd.
} 
En 1993 la situación de la población civil en zonas como el Magdalena Medio y el Meta fue crítica. La población civil era cada vez, con más frecuencia, objeto de la violación de sus derechos por medio de torturas, desapariciones, desplazamiento, etc. Pero no solo fueron víctimas de estos grupos, sino también de grupos guerrilleros como las FARC, ELN y EPL, los cuales tomaban rehenes, secuestraban y fueron los presuntos responsables de masacres a la población civil ${ }^{14}$.

Teniendo en cuenta el papel desempeñado por organismos internacionales en la contribución al desarrollo de nuestro país, es pertinente señalar que, hacia agosto de 1991, el Gobierno de los Estados Unidos suscribió con el de Colombia el convenio de cooperación para implementar la reforma al sector justicia, dentro del cual se enmarca la solicitud realizada por la Agencia de los Estados Unidos para el Desarrollo Internacional -USAID-y el Ministerio de Justicia y del Derecho a la Fundación para la Educación Superior -FESpara la ayuda en el impulso de las actividades y proyectos que "reforzarán las acciones del sector justicia"15, el cual se denominó "Programa para la Modernización de la Administración de Justicia PMAJ".

Dentro del componente de mejoramiento de la efectividad en el funcionamiento de la administración de la rama judicial, se encontraba como proyecto el de Casas de Justicia, que se "presentó como un modelo innovador que llevaría a zonas marginadas y densamente pobladas de las grandes ciudades los servicios de justicia de diversas entidades..."16.
En este convenio, situado entre los programas de la segunda ola o segunda generación promovidos por la USAID en Colombia, en relación con la reforma al poder judicial en su segunda fase, es decir, entre los años 1992 a 1996 en el marco del PMAJ, estuvo latente la necesidad de "enfrentar las deficiencias no solo de la oferta de justicia sino también las que aquejaban a la demanda de justicia (esto es, los múltiples obstáculos que impiden a la mayoría de los ciudadanos tener acceso efectivo a la justicia)"17, preocupación que, según Rodríguez, fue la que originó esfuerzos como la creación de las Casas de Justicia, entendidas como un espacio que concentraba instituciones de justicia y que propendía por la solución pacífica de conflictos en áreas marginales.

Simultáneamente, la innovación constitucional de 1991, que involucró una transformación en la dinámica de la justicia y la consagración de Colombia como Estado social de derecho, trae consigo para el Estado, entre otros, el deber de garantizar a sus asociados un orden más equitativo y legítimo, para lo cual resulta imperativo que los mismos tengan un mejor acceso a un "sistema de justicia eficaz, fundamentado en la igualdad $y$ el respeto a la diferencia, y enmarcado en un ámbito participativo y pluralista"18. Éste es a todas luces el fundamento más importante para la implementación del Programa Nacional de Casas de Justicia, en una sociedad como la colombiana, tan lejana y descreída de sus instituciones y de la justicia.

Hacia 1994 se conforma el equipo técnico del Programa de Justicia al interior de la FES, por cuatro profesionales con trayectoria en el "trabajo de ser-

\footnotetext{
Basado en Informe de Amnistía Internacional 1993, Colombia.

ARANGO DUQUE, Luis Fernando. Casas de Justicia: desarrollo institucional y percepción de los usuarios. Bogotá, 2003, p. 38.

Ibíd., p. 41

RODRÍGUEZ. Op. Cit., p. 40.

Programa Nacional Casas de Justicia y Paz. Ministerio del Interior y de Justicia y USAID. Bogotá, 2005, p. 7.
} 
vicios legales alternativos, trabajo con la sociedad civil, con mucho trabajo dedicado a investigación socio jurídica y personas que tenían una gran experiencia en temas de tecnología y mecanismos alternos de resolución de conflictos ${ }^{19}$. Este equipo estaba compuesto por Annette Pearson de González, Juan Pablo Galeano, César Augusto Solanilla y Luis Ernesto Salinas y dirigido por el Ingeniero Eduardo Aldana Valdés, quienes elaboran la propuesta para la implementación del modelo de Casa de Justicia ante la necesidad constante de hallar soluciones al ineficiente servicio de administración de justicia.

\section{El minotauro acecha: iy la justicia en qué andaba?}

Respecto a la coyuntura judicial y de la administración de justicia, con la apertura económica y la implantación del modelo neoliberal se da la reforma a la justicia por medio de la cual surge, entre otros, el Ilamado Estatuto Antiterrorista, que había sido propuesto por el gobierno del entonces presidente Virgilio Barco, cuyo objetivo era la lucha contra organizaciones narcotraficantes y la guerrilla, afectando las protestas sociales en contra de la privatización de las entidades públicas ${ }^{20}$. Un ejemplo es el caso ocurrido en 1992 con 13 trabajadores de la empresa estatal Telecom, quienes fueron acusados de terroristas por su participación en una huelga realizada en abril del mismo año ${ }^{21}$. Pero no solo se cometieron irregularidades con los empleados de las entidades públicas sino también con la población civil, ya que el mencionado Estatuto Antiterrorista permitió a las fuerzas armadas la detención sin orden judicial, violando así el derecho fundamental al debido proceso y a la legítima defensa consagrados en la Constitución Nacional en el artículo 29, así como también se crearon los denominados Jueces sin Rostro, los cuales utilizaban testigos y pruebas secretas, violando así varios derechos tales como "la presunción de inocencia, el derecho a un juicio público, a confrontar a los testigos del fiscal y a presentar testigos por parte de la defensa".

Otras de las problemáticas surgidas por la implantación de la llamada "apertura económica" fueron las reformas impulsadas desde las concepciones neoliberales de "flexibilización laboral", a las cuales quedaron sometidos los trabajadores como con el llamado "salario integral", el cual consiste en un salario único que el trabajador debe repartir en sus diferentes necesidades de salud, transporte y pensiones, creando con esto una imposibilidad de ahorro, ya que el empleador le quita apoyos en salud, vacaciones, pensión y otros beneficios, para aquellos que en la época recibían más de 10 salarios mínimos, supuestamente con el fin de reducir costos laborales. Además el salario mínimo legal entra a ser discutido cada año por medio de un "acuerdo" entre representantes del gobierno, empleadores y los trabajadores, pero, al no existir consenso entre éstos, se decidiría por decreto presidencial ${ }^{22}$.

El desarrollo de las políticas de modernización del Estado conllevó que muchas personas perdieran sus empleos, pero además generó la privatización de las empresas públicas. Gracias a esto se aprueban una serie de contratos con altos salarios donde los funcionarios del estado implementan políticas clientelistas otorgándoselos a personas cercanas a ellos para convertirlos en sus asesores o consultores, entre otros ${ }^{23}$.

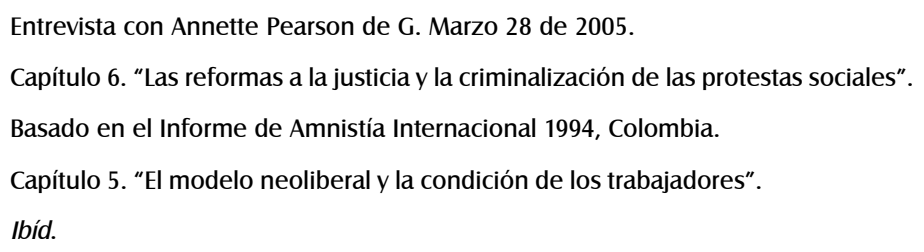


El sector salud también se ve afectado como consecuencia de la aprobación de de la Ley 100 de 1993, empezando a privatizar los servicios de salud. Como consecuencia de la presión que recibía el presidente César Gaviria (en esa época) por parte de las instituciones financieras internacionales, se introducen cambios en la prestación del servicio de salud y seguridad social, como en el tema de las pensiones, alargando el tiempo de servicio y la edad para disfrutar de la pensión, igualmente se incrementa el monto del aporte $y$ el número de semanas cotizadas, con el supuesto objetivo de que las personas se puedan pensionar antes ${ }^{24}$.

Ya se ha dicho que con el incremento en los niveles de pobreza, con la agudización del conflicto interno, del fenómeno del desplazamiento, etc., la población vulnerable ha aumentado y con ello sus carencias y necesidades. Cada vez son más los colombianos que se encuentran en los cinturones de miseria de las ciudades, que buscan una salida rápida y efectiva a sus problemáticas sociales. En esta carrera en contra de la injusticia social, amplios sectores de la población continúan excluidos.

El contexto social, económico, político y jurídico de Colombia, en el momento del nacimiento del Programa Nacional de Casas de Justicia es grave. La brecha entre los invisibles, que cada vez son más, y los sectores privilegiados, que cada vez son menos, se convierte en un abismo. El laberinto se cierra y las esperanzas se van agotando, el minotauro espera paciente...

\section{7. ¡Los invisibles somos más!: panorámica de los sectores sociales en condiciones de grave vulnerabilidad}

Ciudades como Manizales, Medellín, Cali y Bogotá están afrontando la llegada de cientos de indí- genas y afrocolombianos desplazados por la violencia, la miseria y el olvido. Los invisibles también históricamente se han organizado para reclamar sus derechos.

Encontramos en esta búsqueda organizaciones de "Trabajadoras sexuales" en nuestro país. Una de sus líderes, Zulma Manco, nos contaba: "nos organizamos hace diez años para luchar contra el olvido y la doble moral de la sociedad hacia nosotras". Pero igualmente encontramos organizaciones internacionales de trabajadoras/es sexuales que inician en 1986 en Madrid (España) para abrir la puerta del laberinto y burlar al minotauro. La UNESCO organiza un encuentro sobre las causas de la prostitución. A partir de ese momento se realizan congresos sobre el tema en toda Europa y en algunos países americanos. En 1991 se organiza el primer Congreso Europeo de prostitutas en la ciudad alemana de Frankfurt; en 1992 en la ciudad brasileña de Río de Janeiro se realiza el Congreso Latinoamericano de este sector social. Hoy existe un proyecto de Carta Mundial de Derechos de las Prostitutas. Las trabajadoras sexuales invisibles entraron en el laberinto del minotauro o la búsqueda incansable por obtener un reconocimiento legal de sus derechos $y$, como en la leyenda del Minotauro, muchas de estas mujeres nunca podrán salir de este sitio.

La relación que existe entre el trabajo sexual y la trata de personas es igualmente explicada en el Informe: "En los países desarrollados donde el estatus de la mujer ha mejorado, no hay suficientes mujeres que quieran trabajar voluntariamente en la industria del sexo. En consecuencia, la migración para trabajar en la industria del sexo se ha incrementado, pero el hecho de que el trabajo sexual es ilegal para los migrantes en la mayoría de los países aumenta el riesgo de la trata de trabajadoras sexuales migrantes" ${ }^{\prime 25}$.

$\begin{array}{ll}24 & \text { Ibíd. } \\ 25 & \text { Ibíd. }\end{array}$


Los habitantes de la calle también se organizan. De una manera diferente y para algunos coyuntural, pero se ven avances en la consolidación de un incipiente movimiento social. Entre 1998-2000 se inició la "recuperación" de la llamada calle del Cartucho. Al proyecto se le denominó Tercer Milenio. El objetivo era la intervención urbanística en ese sector con el fin de desarticular la economía ilícita del "Cartucho", dado que la mayor parte de ésta giraba alrededor de la venta de drogas consideradas ilegales y del mercado de objetos hurtados. De igual forma, buscó separar la actividad del reciclaje que realizan allí unas cien bodegas y gente especializada en este oficio, para lograr que esta se hiciera en forma tecnificada y digna en otros sitios de Bogotá, bajo las normas del plan maestro de manejo de residuos sólidos que tiene la ciudad.

Durante este proceso se dieron marchas, enfrentamientos, negociaciones y se visibilizaron algunos líderes que ante el asombro de todos, se identificaban como profesionales, abogados y poetas. Uno de estos líderes, "el Cali", fue interlocutor en la administración del Alcalde Peñalosa, y exigía "tratamiento digno, solución al problema de vivienda, salud, educación y empleo". Sin embargo, fue asesinado en circunstancias que no han sido aclaradas. Luego del "Cali" surgieron otros líderes, dos de ellos igualmente asesinados.

Los habitantes de la calle invisibles, ingresaron de manera clara por una de las salidas del laberinto del minotauro cuando se tomaron el antiguo matadero distrital ubicado en la calle 13 con carrera 23 de la ciudad de Bogotá. Desde allí se vieron nuevamente los rostros sonrientes y morenos de sus líderes. Los medios de comunicación registraron el hecho como un grave atentado contra la seguridad y el orden público. Pocas personas vieron este hecho como una acción desesperada de un sector social por la reivindica- ción de sus derechos. Ante la falta de soluciones, se inició un proceso al que se le llama "el efecto cartucho", que podría ser más o menos como el "efecto mariposa" pero sin hogar. Todas estas personas comenzaron a colonizar nuevos barrios tales como: el Voto Nacional, Eduardo Santos, Cundinamarca, San Antonio, Policarpa y las vecindades del la Unidad Residencial Colseguros. Muchos líderes que ingresaron al laberinto nunca salieron de él.

Miles y miles de personas llegan a las calles fruto del desplazamiento forzado. Según fuentes de la Consultoría para los Derechos Humanos y el Desplazamiento Forzado-CODHES-, más de tres millones y medio de compatriotas han sido desarraigados de sus hogares. Para muchos, la calle se convierte en su única opción de vida. La miseria, los elevados índices de pobreza, son el tiquete de entrada de estas personas invisibles al laberinto, el minotauro solo espera...

Un hecho importante es que ya se están impulsando documentos de derechos que intentan superar el tema de la pobreza, discriminación y exclusión en las ciudades, por ejemplo la "Carta Europea de Salvaguarda de los Derechos Humanos en la Ciudad".

La presentación de dicha carta se pregunta:

¿Por qué, en el umbral del siglo XXI, una Carta Europea de los Derechos Humanos en la Ciudad? La Declaración de Derechos Humanos (1948) es universal. ¿No ha sido reforzada y completada por otros muchos compromisos que hacían hincapié en la protección de ciertos derechos de distinto alcance? La Convención Europea (1950) ofrece lo que llamamos una garantía jurisdiccional. Y, sin embargo, existen muchos derechos que no son todavía "efectivos» y a los ciudadanos y ciudadanas les cuesta orientarse en el laberinto de los procedimientos administrativos y jurídicos. ¿Cómo garantizar mejor?, ¿cómo actuar mejor?, ¿cómo asegurar mejor las condiciones públicas para la felicidad privada de cada uno? 
Esta Carta se suscribió inicialmente el 18 de mayo del 2000 en la ciudad de Saint Denis, Francia.

Los recientes sucesos del 27 de octubre de 2005 en Clichy, Francia, son un Ilamado de atención de los invisibles del primer mundo en la búsqueda de una ciudad incluyente, tolerante, igualitaria, democrática y justa. Las noticias se limitan a informar la cantidad de automóviles incendiados, pero el problema es estructural. La Carta Europea de Salvaguarda de los Derechos Humanos en la Ciudad" es tan oportuna como necesaria, aun en los países del norte o "países del bienestar". Los disturbios se han extendido rápidamente y se han unido a muchos sectores sociales invisibles. Francia también tiene sus "cartuchos":

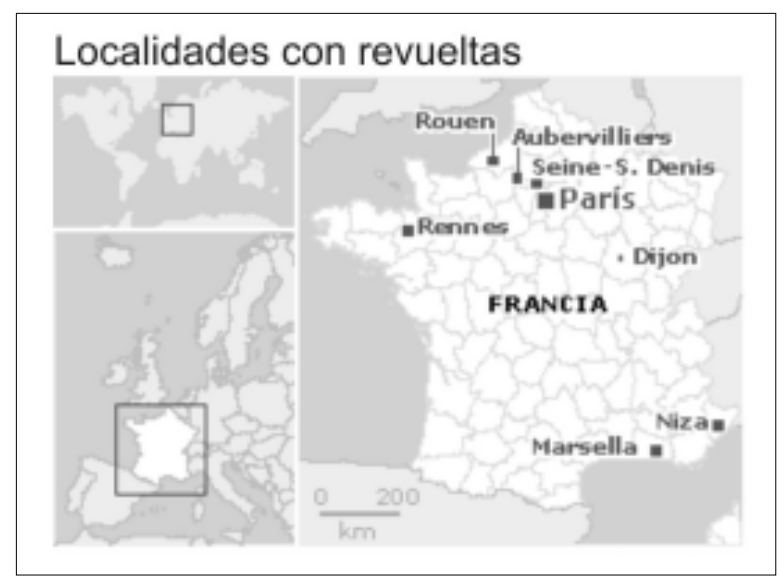

La Carta hace especial énfasis en garantizar los derechos de los grupos más vulnerables y en el desarrollo de la igualdad efectiva. Este tipo de documentos en el cual están comprometidas más de 40 ciudades principales europeas son una herramienta de trabajo para impulsar políticas públicas orientadas a estos grupos sociales, pero también es una evidencia de que aún en Europa la pobreza, la exclusión y el racismo están creciendo.

Los desplazados en Colombia, además de invisibles son irreconocibles, a pesar de que la ley 387 de 1997 en su Art. $1^{\circ}$ define a la persona desplazada como:
Es desplazado toda persona que se ha visto forzada a migrar dentro del territorio nacional abandonando su localidad de residencia o actividades económicas habituales, porque su vida, su integridad física, su seguridad o libertad personales han sido vulneradas o se encuentran directamente amenazadas con ocasión de las siguientes situaciones: conflicto armado interno, disturbios y tensiones interiores, violencia generaliza$\mathrm{da}$, violaciones masivas de los derechos humanos, infracciones al Derecho Internacional Humanitario u otras circunstancias que puedan alterar o alteren drásticamente el orden público.

El derecho fundamental a la libre circulación y libre elección de residencia imponen la prohibición de causar desplazamiento por la fuerza, aún en situaciones de conflicto armado, como garantía de toda persona que ostenta la calidad de no combatiente. Por ende, debe ser respetada por los agentes armados generadores del conflicto. El Art. $2^{\circ}$ del Protocolo II de Ginebra al respecto establece: "No se podrá ordenar el desplazamiento de la población civil por razones relacionadas con el conflicto, a no ser que así lo exija la seguridad de las personas civiles, o razones militares imperiosas. Esta prohibición en virtud del Derecho Internacional Humanitario debe ser respetada por todos los grupos y fuerzas armadas en conflicto".

Como comenta Bustillo Melgarejo: “...la población desplazada es víctima de violaciones a derechos humanos, de infracciones al Derecho Internacional Humanitario, de crímenes de guerra y de delitos, por ende existe para el Estado la obligación de esclarecer la verdad, impartir justicia y reparar los daños causados a estas víctimas".

A su vez en la ley 387 se establecen las obligaciones de las autoridades en garantía del acceso a la justicia y a la reparación antes y durante el desplazamiento. Señala su artículo $\mathbf{8}^{\circ}$ :

Las acciones de prevención que deberán emprender los comités municipales, entre otras, serán: 
1. Acciones jurídicas. Los miembros del comité municipal deberán orientar a las comunidades que puedan verse afectadas por un hecho de desplazamiento, en la solución, por vías jurídicas e institucionales, de los conflictos que pueda generar tal situación. Así mismo, analizarán la viabilidad de las acciones jurídicas y recomendarán o decidirán la interposición oportuna de los recursos constitucionales o legales pertinentes que permitan minimizar o erradicar procesos embrio-narios de persecución o violencia.

2. Los miembros del comité municipal tratarán de prevenir los procesos embrionarios de desplazamiento proponiendo mecanismos alternativos de solución de conflictos.

3. Acciones asistenciales. Los miembros del comité municipal deberán evaluar las necesidades insatisfechas de las personas o comunidades que eventualmente puedan precipitar un proceso de desplazamiento forzado. Deberán, con base en dicha evaluación, tomar las medidas asistenciales del caso.

Los adultos mayores, limitados por escenarios sociales donde son excluidos y maltratados (ser viejo es sinónimo, para el común de la sociedad, de no-productividad, de enfermedad, de lentitud, de incapacidad, de dependencia, de carencias e incluso de discapacidades) ${ }^{26}$, se ven en la necesidad de aislarse, de convertirse en habitantes de la calle y otros solamente esperan su muerte. Pese a este fenómeno, las tasas de longevidad siguen aumentando "en el año 2000, una de cada 10 personas tiene 60 años o más, en el año 2050, 1 de cada 5 personas tendrá 60 años o más, y en el 2150 la proporción será de 1 de cada 3 personas; igualmente se puede observar que las personas con 80 años o más constituyen el $11 \%$ de la población. En el 2050, un $27 \%$ de la población

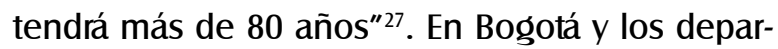
tamentos de Antioquia y Valle del Cauca se con- centra la mitad de la población que está por encima de 60 años (Asociación Federativa, 1997).

El laberinto legal, de las formalidades, de las competencias, de la falta de voluntad política, de la ausencia casi total de recursos, el laberinto llamado acceso a la justicia, allí donde muchas veces mueren los sueños de los invisibles, pero también el laberinto donde se han logrado materializar y reconocer derechos de otros invisibles, he allí la gran paradoja.

\section{Recorridos por el laberinto: planeando la fuga}

El recorrido por los sitios donde los invisibles sociales tratan de salir del laberinto jurídico logrando el restablecimiento de sus derechos nos llevó a ciudades como Cartagena, Valledupar, Barranquilla, Quibdó, Popayán, Pereira y Cali, etc. De cada una de estas ciudades aprendimos mucho, charlamos con los usuarios, los coordinadores, los funcionarios, realizamos entrevistas, aplicamos encuestas, elaboramos estudios de caso, en fin, diversas actividades que han dejado un sinnúmero de lecciones aprendidas, que nos permiten ir avanzando hacia la consolidación del Protocolo de Atención para Sectores en Condiciones Especiales de Vulnerabilidad en el Programa Nacional de Casas de Justicia.

Existe en este momento una experiencia significativa que nos permitirá progresar hacia este objetivo en temas como el indígena y el afro-coIombiano. Esta posibilidad se puede consolidar a partir del modelo de Casa de Justicia Regional. Esta nueva mirada incorpora las iniciativas departamentales superando la acción local y se proyecta como una fuente de soluciones regionales, más estructurales. La primera Casa de Justicia Regional beneficiará a las poblaciones de

\footnotetext{
26 Documento gris de la Defensoría del Pueblo. Tercera edad.

$27 \quad$ Ibíd.
} 
Chaparral, Ataco, Ortega y Rioblanco en el departamento del Tolima. Para alcanzar las metas de garantizar el acceso a la justicia de estas poblaciones se requiere de altos niveles de coordinación interinstitucional entre alcaldes, gobernadores y el nivel central. La sede central estará ubicada en Chaparral y los tres puntos satélites en cada uno de los otros municipios. Se pretende la elaboración de un Plan Regional de Justicia que será el resultado del estudio y concertación de los cuatro municipios, sus habitantes, organizaciones sociales y sus autoridades.

Esta nueva posibilidad es de gran importancia, ya que la mayoría de dificultades de acceso a la justicia que tienen especialmente los pueblos indígenas y las comunidades afrocolombianas no se encuentran en los cascos urbanos de las capitales de los departamentos, sino en las ciudades más pequeñas. La concepción regional permitirá, en estos casos, adelantar planes y programas que tengan en cuenta la unidad cultural de estos pueblos, que en la generalidad de los casos va más allá de los límites de un municipio.

Se planteó que la elaboración del Protocolo de Atención, dirigido a los sectores mencionados como producto final de esta investigación, se debe concebir como una acción afirmativa del Estado frente a dichos grupos marginados sistemáticamente. Este tipo de acciones identificadas han sido caracterizadas por el Tribunal Constitucional Colombiano como la posibilidad de:

...designar políticas o medidas dirigidas a favorecer a determinadas personas o grupos, ya sea con el fin de eliminar o reducir las desigualdades de tipo social, cultural o económico que los afectan, bien de lograr que los miembros de un grupo subrepresentado, usualmente un grupo que ha sido discriminado, tengan una mayor representación.

\begin{abstract}
La jurisprudencia ha hecho énfasis en que el trato diferencial positivo no sólo responde a los fundamentos del Estado social de derecho, que se traducen en el deber del Estado de proteger a las personas que por su condición económica, física o mental, se encuentren en circunstancias de debilidad manifiesta, sino que con ellas se atiende el mandato expreso del artículo 13 superior para hacer que la igualdad sea real y efectiva (incisos $2^{\circ}$ y $3^{\circ} \mathrm{del}$ art. 13 de la Constitución Política) ${ }^{28}$.
\end{abstract}

Una acción afirmativa con elementos étnicos, culturales, de género y generacionales diferenciales: el derecho fundamental al acceso a la justicia debe ser interpretado y llevado a la práctica con estos mínimos requisitos de respeto. Cada uno de los sectores evidencia un hecho diferencial, sus necesidades de acceso a la justicia no son las mismas, sus posibilidades de acceder y condiciones tampoco, es decir, el Estado no puede hacer la misma oferta institucional a cada uno de estos sectores. En consecuencia, tiene que tener en cuenta la situación particular de cada grupo al momento de planear, implementar y ejecutar políticas dirigidas a la satisfacción de los derechos y por lo tanto al cumplimiento de sus obligaciones. Para avanzar en este fundamento hemos intentado rastrear las fuentes de este concepto y los ejemplos en su aplicación. Lo novedoso no es el concepto de acción afirmativa, sino el deseo de ampliar sus alcances hasta las mismas Casas de Justicia, con una oferta desde la administración de justicia a estos sectores.

En atención a lo anterior y a las particularidades de cada sector se consideró pertinente nutrirla de elementos étnicos, culturales, de género y generacionales - diferenciales- admitiendo una interpretación plural e incluyente del derecho fundamental de acceso a la justicia que propenda por el reconocimiento, garantía y protección de medidas mínimas de respeto de la diferencia.

28 Corte Constitucional. Sentencia C-174 de 2004, C-1036 de 2003, C-331 de 2003. 


\section{Algunos conjuros para exorcizar la invisibilidad}

\section{A. El contenido material del derecho fundamental al acceso a la justicia}

El acceso a la justicia como derecho fundamental, la aproximación a las Casas de Justicia desde su marco conceptual como unidad de análisis y la creación de un protocolo a partir de la filosofía de acción afirmativa generaron la integración de diversos conceptos y teorías para plantear el parámetro de referencia en el que los investigadores se sintieran identificados para desarrollar la investigación y el trabajo de campo de la misma.

Para comprender las trasformaciones del derecho a acceder a la justicia es necesario reseñar brevemente los contextos socio jurídicos que se vivieron a partir de la década de los noventa.

La Constitución de 1991 nace en un contexto de transición de las ideas políticas y jurídicas que hasta ese entonces predominaban en el país. Las características propias del Estado colombiano generaban un ambiente propicio para la discriminación, la intolerancia y la concentración del poder económico y social. Esta concepción hacía que cada vez más se alejara el Estado y el derecho de la sociedad civil. Sectores como los pueblos indígenas, afrocolombianos, partidos políticos independientes, entre otros, eran invisiblizados $y$ desprotegidos, produciendo en gran parte de la población anomia jurídica y una crisis del Estado y sus instituciones.
De igual forma, en la década de los noventa, el derecho internacional trasforma su concepción acerca de los derechos humanos. La Convención de Viena abrió las puertas para superar la historia de división de los derechos subjetivos que ha conllevado a clasificaciones y discriminaciones, que ante las condiciones dramáticas de los contextos sociales mundiales resulta insuficiente, con la sola garantía de defensa de los derechos civiles y políticos, para proporcionar las condiciones para el desarrollo de una vida digna. Los derechos económicos, sociales y culturales son una de las principales carencias de los sectores vulnerables. La educación, el trabajo y el respeto a la cultura, entre otros, permiten, al interrelacionarse con los derechos de primera generación, crear unas mínimas circunstancias para una sociedad que clama por un entorno justo y digno ${ }^{29}$.

Estas trasformaciones permitieron la creación de instrumentos y mecanismos para hacer efectivos los derechos fundamentales en su totalidad, los cuales protegen y regulan la vida social, que hasta el momento se encontraban olvidados por el formalismo ontológico de la ley. El derecho a acceder a la justicia, al ser concebido como la materialización de los principios constitucionales y parámetro para establecer cuál es la legitimidad del Estado, sus normas e instituciones, es uno de los derechos que evidencian profundos cambios en su concepción, consolidándose como pilar del Estado social de derecho ${ }^{30}$, y de ineludible cumplimiento en aras de alcanzar la efectiva

29 La Corte Constitucional en repetidas ocasiones se ha pronunciado resaltando la conexidad de los Derechos Humanos, principalmente cuando sectores vulnerables no tienen posibilidades de una realización plena de sus derechos por circunstancias propias de la situación especial que afrontan. Entre las sentencias más significativas de desplazamiento se encuentra la T-327-2001, en la que la Corte manifestó:

En numerosas disposiciones constitucionales, que también encuentran reiteración en tratados internacionales sobre derechos humanos, se contempla la protección a elementales garantías y derechos de la persona, como el de la vida en condiciones de dignidad, la salud en conexión con ella, la integridad personal, la libre circulación por el territorio nacional, el trabajo, el derecho a una vivienda digna, la educación, la alimentación mínima, la prohibición del destierro, entre otros.

30 Sentencia C-426-2002 “...el derecho de acceso a la administración de justicia constituye un pilar fundamental de la estructura de nuestro actual Estado Social de Derecho, en cuanto contribuye decididamente a la realización material de sus fines esenciales e inmediatos, como son, entre otros, los de garantizar un orden político, económico y social justo, promover la convivencia pacífica, velar por el respeto a la legalidad y a la dignidad humana y asegurar la protección de los asociados en su vida, honra, bienes, creencias y demás derechos y libertades públicas (C.P. arts. $1^{\circ}$ y $\left.2^{\circ}\right)^{\prime \prime}$. 
realización del universo de derechos tales como salud, educación, servicios públicos, trabajo, vivienda digna, etc.

La constitución del acceso a la justicia como un derecho subjetivo ha permitido reconocer características que lo identifican y de igual forma le permiten adquirir mayores alcances en la doctrina y en la jurisprudencia: la identificación del sujeto titular del derecho (personas naturales o jurídicas), la efectividad en su desarrollo ${ }^{31}$, la aplicabilidad inmediata ${ }^{32}$ y unos mínimos preceptos formales y materiales que proporcionen seguridad jurídica. Así mismo, este derecho contiene los requisitos esenciales (T-406 de 1992) de todo derecho fundamental.

\section{B. La justicia de proximidad: una justicia más cerca del corazón de los ciudadanos y ciudadanas}

Otro concepto que hemos intentado apropiar es el de justicia de proximidad, propuesta que han venido desarrollando las Casas de Justicia en Francia, como lo afirma el profesor Luis Fernando Arango Duque: "Se busca con las Casas de Justicia, que la justicia sea más cercana, más accesible y más comprensible para los ciudadanos, Io que se encamina directamente a solucionar barreras que impiden el acceso de los ciudadanos a la justicia"133. En las Casas de Justicia francesas tienen espacio las asociaciones de víctimas, psicólogos, incluso hay servicios médicos y sociales, atienden con especial relevancia el tema de las pandilla juveniles y las personas en situación de indigencia, "Más allá de la visión de una justicia únicamente represiva se trata de mantener un papel preventivo, de información jurídica, y aun de protección (en particular contra los abusos de la policía)" ${ }^{\prime 34}$.

La proximidad es un concepto que supera el ámbito espacial, territorial y se inscribe en la esfera de la calidez, cobertura, presencia, importancia, es un avance de lo formal a lo material. La proximidad, como un puente o "carril rápido" para que los ciudadanos y ciudadanas, en este caso sectores históricamente vulnerables, puedan ejercer sus derechos humanos. Ver las Casas de Justicia en Colombia como una posibilidad de aproximación a la realidad, como testigo y gestor de un proceso de inclusión, es una posibilidad que está allí, en potencia en nuestras Casas de Justicia y Paz.

Una proximidad que en el caso colombiano podría recoger de las experiencias de las Casas de Justicia de varios países latinoamericanos. Las casas de justicia de Guatemala y Perú han desarrollado programas en los idiomas de los pueblos indígenas de la región, en coordinación con las autoridades tradicionales ancestrales, aplicando el derecho propio de dichos pueblos. En Ecuador se tienen programas de fortalecimiento en la sociedad civil. Nicaragua intenta, desde sus Casas de Justicia, consolidar los acuerdos de paz y tienen un marcado énfasis en la defensa, promo-

\footnotetext{
31 Al respecto la jurisprudencia se ha pronunciado en Sentencia C-037-1996: "El acceso a la administración de justicia implica, entonces, la posibilidad de que cualquier persona solicite a los jueces competentes la protección o el restablecimiento de los derechos que consagran la Constitución y la ley. Sin embargo, la función en comento no se entiende concluida con la simple solicitud o el planteamiento de las pretensiones procesales ante las respectivas instancias judiciales; por el contrario, el acceso a la administración de justicia debe ser efectivo, lo cual se logra cuando, dentro de determinadas circunstancias y con arreglo a la ley, el juez garantiza una igualdad a las partes, analiza las pruebas, llega a un libre convencimiento, aplica la Constitución y la ley y, si es el caso, proclama la vigencia y la realización de los derechos amenazados o vulnerados ${ }^{65}$ (cursiva por fuera del texto original)

32 Sentencias T- 006 de 1992, C-037-96, entre otras.

33 ARANGO DUQUE, Luis Fernando. Casas de Justicia: desarrollo institucional y percepción de los usuarios. Fundación Cultural Javeriana de Artes Graficas - JAVEGRAF. Bogotá, 2003, p. 63.

$34 \quad$ Ibíd., p. 64.
} 
ción y protección de los derechos humanos. Profundizando en este tema podremos construir un contenido para las Casas de Justicia en Colombia más próximo a la realidad.

Francia ha desarrollado un tipo de justicia de proximidad orientada hacia un mayor acercamiento a las víctimas del delito y a la facilitación del acceso a consultas legales, para lo cual se han creado diversos organismos, como los Consejos Departamentales de Acceso al Derecho, para proporcionar consulta legal y agilización de procedimientos. Las Casas de Justicia y Derecho, las cuales generan una mayor proximidad entre la justicia $y$ el ciudadano, interviniendo también con medidas de mediación penal y reparación.

Igualmente, en España se ha venido desarrollado el concepto de Justicia de proximidad, teniendo como referente a Francia y con el objetivo principal de descargar de trabajo a los órganos de primera instancia de instrucción, atribuyendo parte de sus actuales competencias -las de menor entidad- a otros órganos judiciales de nueva creación, los juzgados de proximidad, que se establecen sólo en municipios con más de 250.000 habitantes, en capitales de provincia de más de 150.000 habitantes, o municipios de especiales condiciones sociales, económicas, históricas o culturales de 75.000 habitantes y siempre en aqueIlos casos en que la Comunidad Autónoma respectiva haya asumido competencias en justicia. Los jueces de proximidad no provienen de la carrera judicial, no se requiere que sean licenciados en derecho y resuelven las pequeñas faltas de orden penal y reclamaciones civiles de menor cuantía.

La justicia de proximidad es una apuesta por la defensa, promoción y garantía de los derechos humanos. Una dificultad que se nos ha manifestado por parte de varios de los expertos en el tema sería la imposibilidad de ofrecer nuevos servicios o programas desde el Programa Nacio- nal de Casas de Justicia sin afectar el marco normativo, especialmente el Decreto 1477 de agosto de 2000, que define, entre otros asuntos, los objetivos, servicios y entidades participantes de las Casas de Justicia. Sin embargo, creemos que no es necesaria la reforma del Decreto sino una interpretación más generosa de dicha normatividad.

El artículo $3^{\circ}$ del Decreto 1477 de 2000, establece como uno de los objetivos del Programa en su numeral 10: "promover la defensa de los derechos humanos de los miembros de la comunidad". Este proyecto no tiene otro objetivo que facilitar, por medio de Protocolos de Acción Coordinada, que el Programa cumpla a cabalidad con este objetivo.

Igualmente, al leer el artículo $4^{\circ}$, que define los servicios que deben prestar las Casas de Justicia, se establece en el numeral $1^{\circ}$ : "orientar e informar, de derechos humanos y obligaciones legales, con énfasis en protección de la familia y el menor". Igualmente, queda establecida una especie de "cláusula abierta" al señalar en el numeral 7 del mismo artículo: "Todos los demás servicios que se consideren necesarios para el cumplimiento de los objetivos del Programa Casas de Justicia".

\section{Logros parciales del proyecto de investigación}

Este proyecto ya tiene sus primeros resultados concretos. Es decir, no se espera que esté terminado para intentar influir en la creación e impulso de políticas públicas que propendan por el restablecimiento de los derechos de los sectores sociales en condiciones de grave vulnerabilidad, tarea del programa de Casas de Justicia.

A. Esfuerzos importantes como el Proyecto de Ley Estatutaria de Igualdad y no Discriminación o "Estatuto antidiscriminación", liderado, entre otras entidades, por la Defensoría del Pueblo, que intenta sentar las bases para una 
sociedad incluyente y respetuosa de la diferencia.

Para elaborar e impulsar el Estatuto se ha conformado un grupo de trabajo con organizaciones de la sociedad civil, que representan a diferentes grupos históricamente discriminados, como la Red Nacional de Mujeres, la Corporación Derechos para la Paz (CDPaz), el Proceso de Comunidades Negras (PCN), Ketlënan Nacional Asociation (KETNA), el Proceso Organizativo del Pueblo Rom (ProRom), la Organización Nacional Indígena de Colombia (ONIC), la Fundación CINDA, la Federación Nacional de Sordos de Colombia (Fenascol), la Asociación Colombiana de Sordociegos (SURCOE), el Instituto Nacional para Sordos (INSOR), el Instituto Nacional para Ciegos (INCI), la Asociación Colombiana para el Desarrollo de Personas con Discapacidad (ASCOPAR), la Federación de Discapacitados Físicos (Fecodif), el Centro de Atención para el Lesionado Medular (Calem), el Proyecto Colombia Diversa, el Proyecto Agenda Gays, Lesbianas, Bisexuales y Transgeneristas, la Fundación FIDES, la Fundación Eudes y la Fundación Esperanza. Ese grupo, con el apoyo de Managment Sciences for Development Colombia (MSD), está llevando a cabo este proceso encaminado a la construcción de propuestas jurídicas, políticas y pedagógicas, entre otras, en torno al tema.

Los integrantes del grupo de investigación hemos participado de manera activa en las últimas reuniones y aportado algunos de los hallazgos de la investigación, especialmente en sectores que no están representados en el grupo de impulso y discusión, como son los habitantes de la calle y trabajadores/ as sexuales, además presentamos un documento proponiendo algunas modificaciones al articulado y la inclusión de capítulos. Los aportes del Grupo de Investigación han sido muy bien recibidos por los miembros del Comité de Impulso del Estatuto.

B. La Sentencia T - 025 del 2004 ha originado un nuevo impulso para la posible solución del desplazamiento forzado, flagelo que afecta a más de 3 millones de compatriotas actualmente. La Corte Constitucional ha convocado a dos audiencias para verificar el estado de cumplimiento de la Sentencia y a pesar de "encontrar grandes avances" la Corte señala que "aun no se ha superado el estado de cosas inconstitucional declarado en la Sentencia T - 025 del 2004". El grupo de investigación ha participado en estos debates e incluso ya hemos planteado la posibilidad de implementar, en algunas ciudades, un Protocolo de atención desde las Casas de Justicia, ya que en la mayoría de las Casas que hemos visitado un porcentaje importante de usuarios son personas desplazadas por la violencia que acuden a la casa por múltiples asuntos, de tal manera que existe una dispersión de funciones y programas de diferentes entidades para con este sector de la población.

C. El Ministerio del Interior y de Justicia, con el que tenemos un Convenio de apoyo para el Proyecto, nos ha invitado a reuniones de gran importancia para el desarrollo final del mismo. Uno de ellos fue el "Encuentro Nacional de Casas de Justicia", donde no solo presentamos la investigación a los coordinadores de las 40 Casas de Justicia del país, sino que además recibimos aportes y fortalecimos las metodologías de trabajo. Tres fueron los resultados concretos que se recogieron de la participación en este evento:

- Se consolidó la elaboración de los "Planes Integrales de Convivencia" como posibilidad de motivar el conocimiento mutuo, el diálogo y las posibilidades de 
trabajo conjunto entre las Casas, sus habitantes y las organizaciones del entorno de la Casa. De esta manera, la participación activa permite que los habitantes y las organizaciones locales puedan definir sus prioridades y proponer soluciones a los problemas más apremiantes de las comunidades. En este sentido, los PIC serán un aliado especial para la elaboración y posterior implementación del Protocolo de Atención fruto final de este proyecto.

- Se presentó el proyecto "Atención Integral a la Violencia Intrafamiliar y Sexual en las Casas de Justicia". Las estadísticas a nivel nacional muestran que el grueso de las actividades de las Casas de Justicia giran en torno a problemas relacionados con la violencia intrafamiliar. El proyecto intenta articular la respuesta integral de las diferentes entidades desde los diferentes sistemas de justicia, salud, educación, protección y restablecimiento de derechos a las víctimas y sobrevivientes de la violencia intrafamiliar y la violencia sexual. Al analizar las variables definidas por el proyecto notamos que desde luego está centrado en las mujeres, niñas y niños, principales sujetos de estas formas de violencia, sin embargo es claro que un alto porcentaje de la población de las ciudades que se visitaron está conformado por adultos mayores, quienes tienen niveles de vulnerabilidad altos y son víctimas cada vez más frecuentes de la violencia intrafamiliar. Por esta razón, solicitamos al Ministerio del Interior y de Justicia incluir variables que den cuenta de la magnitud de esta forma de violencia e incorporar al proyecto acciones de protección a los ancianos víctimas y sobrevivientes de estas formas de violencia. El Ministerio ha tomado muy en serio nuestro aporte y ya estamos convocados a trabajar con los coordinadores del Proyecto Atención Integral a la Violencia Intrafamiliar y Sexual en las Casas de Justicia para coordinar la inclusión de estas nuevas variables.

- Uno de los compromisos del Estado coIombiano respecto a la Convención Internacional contra la Trata de Personas y en cumplimiento de la Ley 958 de 2005 , es el desarrollo de estrategias y políticas públicas contra la trata de personas y de atención y protección de las víctimas de la misma. Por este motivo se está impulsando una estrategia para involucrar a las Casas de Justicia en el desarrollo de estos compromisos. A pesar de que aun no está definido el cómo se va a hacer esta articulación, nosotros como Grupo de investigación de la Universidad Santo Tomás estamos proponiendo que parte de las estrategias de prevención se realicen con las / los trabajadoras/es sexuales, ya que según el Informe de la Alianza Global Contra la Trata de Personas: "EI análisis de las diversas causas que Ilevan a la trata de personas nos ayuda a comprenderlo mejor y a implementar medidas de prevención para eliminar la trata $^{\prime \prime 35}$. En este sentido, el estudio afirma "Indudablemente, la promoción del turismo sexual como estrategia de desarrollo también es un factor que contribuye a la trata de personas para propósitos de prostitución. No se pretende equiparar el turismo sexual con la trata. No obstante, existe una conexión entre el flujo

35 Alianza Global contra la Trata de Personas. Manual de derechos humanos y trata de personas. OIM. Bogotá, 2004, p. 55. 
de extranjeros relativamente pudientes en busca de sexo en los países en vías de desarrollo y el desplazamiento de las mujeres hacia la industria del sexo para satisfacer esta demanda"36.

D. En la búsqueda de los elementos del Protocolo de Atención a Sectores Especialmente Vulnerables en el Programa Nacional de Casas de Justicia y (ahora) de Convivencia Ciudadana, asistimos a la reunión de consultorios jurídicos que atienden a personas en situación de desplazamiento forzado, convocada por el Instituto Latinoamericano de Servicios Legales Alternativos -ILSA-, cuyo objetivo era evaluar la efectividad y validez de los procedimientos que se han venido utilizando para atender a este sector social y especialmente fortalecer la red de consultorios jurídicos que están desarrollando acciones a favor de la población desplazada. Uno de los aspectos que incluiremos en el Protocolo es el papel de los Consultorios Jurídicos que hacen presencia en las Casas de Justicia frente a los sectores más vulnerables de la población colombiana.

Estos resultados permiten que el Protocolo de Atención de Sectores Vulnerables en las Casas de Justicia y Paz tenga posibilidades reales.

\section{BIBLIOGRAFÍA}

ARANGO DUQUE, Luis Fernando. Casas de Justicia: desarrollo institucional y percepción de los usuarios. Bogotá: Javegraf, 2003.

ARAUJO RENTERÍA, Jaime. Teoría de la Constitución. Bogotá: Ecoe, 1996.

BANCO INTERAMERICANO DE DESARROLLO E INSTITUTO INTERAMERICANO DE DERECHOS HUMANOS. Acceso a la justicia y equidad: estudio en siete países de América Latina. San José, Costa Rica. 2000

BONILLA-CASTRO, ElsSy y RODRÍGUEZ SEHK, Penélope. Más allá del dilema de los métodos. La investigación en ciencias sociales. Bogotá: Uniandes-Norma, 2a. ed, 1997.

BORRERO GARCÍA, Camilo (Editor). Justicia alternativa. Estudios de caso. Bogotá: Antropos, 2003.

BUSTILLOS MELGAREJO, Juan Manuel. Cartilla para la capacitación a organizaciones de población en situación de desplazamiento forzado. Bogotá: Publicación Conjunta de ACNUR, Defensoría del Pueblo y la Oficina de Cooperación EUROPEAID, 2003.

CASTRO, Luis. "La teoría del acceso a la justicia: perspectiva histórico comparativa". En: Justicia y pobreza en Venezuela. Caracas: Monte Ávila, 1995.

Censo Nacional de Casas de Justicia y Presencia Institucional - Casas de Justicia. Informe Anual 2002. Ministerio del Interior y de Justicia, Agencia de los Estados Unidos para el Desarrollo (US, AID), Programa de Fortalecimiento y Acceso a la Justicia.

Censo Nacional de Casas de Justicia y Presencia Institucional - Casas de Justicia. Informe Anual 2003. Ministerio del Interior y de Justicia, Agencia de los Estados Unidos para el Desarrollo (US, AID), Programa de Fortalecimiento y Acceso a la Justicia.

CONSEJO SUPERIOR DE LA JUDICATURA -Sala Administrativa-, DANE. Derecho de acceso al servicio de justicia. Primera encuesta nacional de justicia, 1997. Santafé de Bogotá, 1998. 
CORPORACIÓN EXCELENCIA EN LA JUSTICIA. Justicia y desarrollo. "Debate: paz y democracia el aporte de la justicia comunitaria y de paz". No. 10. Bogotá: Corporación Excelencia en la Justicia, 1999.

DE FERRANTI, David, et. al. Desigualdad en América Latina: ¿Rompiendo con la historia? Bogotá: Alfaomega Colombiana - Banco Mundial, 2005.

DE SOUSA SANTOS, Boaventura y GARCÍA VILLEGAS, Mauricio. El caleidoscopio de las justicias en Colombia. Bogotá: Siglo del Hombre, Tomo I, 2001.

DEFENSORÍA DEL PUEBLO y MINISTERIO PÚBLICO. Situación de la niñez explotada sexualmente en Colombia. Bogotá: Presencia, 1995.

DEFENSORÍA DEL PUEBLO. Estado social y democrático de derecho y derechos humanos. Bogotá: Defensoría del Pueblo, 2001.

FAJARDO SÁNCHEZ, Luis Alfonso. Multiculturalismo y derechos humanos. Una perspectiva desde el pueblo indígena Wiwa de la Sierra Nevada de Santa Marta. Bogotá: Documentos ESAP, 1998

"Will Kymlicka y Saturnino Moreno se van por correría por el atrato, o la crónica de los olvidos del discurso multicultural". En: La justicia comunitaria como ruta para la democracia-Memorias II Conferencia Internacional de justicia comunitaria. Bogotá: Red de Justicia Comunitaria y Tratamiento del Conflicto, 2005.

"La juridiversidad en Colombia: un recurso social renovable y en reconstrucción". Documento presentado en el Congreso de Filosofía Latinoamericana. Universidad Santo Tomás, Bogotá, julio de 2005.
FUENTES HERNÁNDEZ, Alfredo (Editor). Reforma judicial en América Latina, una tarea inconclusa. Santafé de Bogotá: Corporación Excelencia en la Justicia, 1999.

GARAY, Luis Jorge (Coordinador general). Repensar a Colombia: hacia un nuevo contrato social. Bogotá: Agencia Colombiana de Cooperación Internacional, PNUD, 2002.

GRANADOS SARMIENTO, Ricardo. Construcción sistémica de justicia: su aplicación en el Programa de Casas de Justicia en Colombia. Bogotá: Universidad de los Andes, 2003.

Informes Anuales del Defensor del Pueblo al Congreso de la República. Años 1994, 1995 y Tomo I, 1996.

INSTITUTO SER DE INVESTIGACIÓN. Casas de Justicia de Aguablanca en Cali y Ciudad Bolívar en Santafé de Bogotá. Informe Final, 1996.

LÓPEZ OSPINA, Gonzalo. Breve diccionario constitucional. Pereira: Papiro, 3a. ed., 1999.

MINISTERIO DE JUSTICIA Y DEL DERECHO. Casas de Justicia. Manual operativo. Santafé de Bogotá, 2000.

MINISTERIO DEL INTERIOR Y DE JUSTICIA. Guía para implantar nuevas Casas de Justicia. Ministerio del Interior y de Justicia, 2004.

MINISTERIO DEL INTERIOR Y DE JUSTICIA. Justicia bajo un mismo techo. Proyecto pedagógico para la vinculación entre la comunidad y las Casas de Justicia. Bogotá, 2004.

MINISTERIO DEL INTERIOR Y DE JUSTICIA. Programa Nacional Casas de Justicia y Paz. Ministerio del Interior y de Justicia, 2005.

MONCAYO, Víctor Manuel, et. al. El debate a la Constitución. Bogotá: Universidad Nacional de Colombia - ILSA, 2002. 
PASARA, Luis (compilador). En busca de una justicia distinta. Experiencias de reforma en América Latina. Lima: Justicia Viva, 2004.

PÉREZ PERDOMO, Rogelio. Acceso a la justicia en la sociedad contemporánea: un análisis de derecho comparado (en copias)

PNUD. Conflicto: callejón con salida. Informe Nacional de Desarrollo Humano Colombia. Bogotá, 2003.

ROCHE, Carmen Luisa (coordinadora). Estudio sobre acceso de personas de escasos recursos a la justicia. Caracas: Universidad Central de Venezuela, 2001 (en copias).

RODRÍGUEZ, César. "El regreso de los programas de derecho y desarrollo". En: El otro derecho: nuevos rumbos en la administración de justicia. ¿Quo vadis justitia? No. 25 (diciembre-2000) Bogotá: ILSA, 2000.

RUIZ SÁNCHEZ, Carlos Ariel. Donde estemos estamos con el pensamiento propio. Elementos de jurisdicción especial indígena y prácticas comunitarias de justicia. Funcop, Red de justicia Comunitaria, AESCO, Popayán, 2001.

SABINO, Carlos A. El proceso de investigación. Bogotá: Panamericana, 3a. ed., 1997.

ZAMBRANO CETINA, William. "Proyecto Casas de Justicia. Diagnóstico administrativo y jurídico" (borrador para la discusión). Programa para la Modernización de la Administración de Justicia FES/ AID, 1996. 